\title{
URINA DE VACA INFLUENCIA O CRESCIMENTO DE MUDAS DE ALFACE CRESPA NO SUDOESTE DO PARANÁ?
}

\author{
COW URINE INFLUENCE THE GROWTH OF LOOSELEAF LETTUCE \\ SEEDLINGS IN THE SOUTHWEST OF PARANÁ? ${ }^{\circ}$
}

\section{INFLUYE LA ORINA DE VACA EN EL CRESCIMIENTO DE PLÁNTULAS DE LECHUGA CRESPA EN EL SUROESTE DE PARANÁ? ${ }^{\circ}$}

Recebido em: 25/11/2020 - Aprovado em: 13/01/2021 - Publicado em: 20/04/2021

doi) http://dx.doi.org/10.18011/bioeng2021v15n1p142-153

Ricardo Júnior Marangon ${ }^{1}$ (ricardo_marangon@yahoo.com.br)

Marcelo Dotto' (marcelo.dotto@unisep.edu.br)

Allan Remor Lopes' (allanremorlopes@gmail.com)

Camila Moreno Giarola² (camila.giarola@edu.unipar.br)

Kelli Pirola3 (kelli_pirola1@hotmail.com)

1 Centro Universitário UNISEP. Dois Vizinhos, PR, Brasil.

2 Universidade Paranaense. Umuarama, PR, Brasil.

3 Universidade Tecnológica Federal do Paraná. Pato Branco, PR, Brasil.

\section{RESUMO}

A utilização de urina de vaca pode ser considerada uma prática de baixo custo para os produtores rurais do Sudoeste do Paraná. Assim objetivou-se com este trabalho avaliar o efeito da urina de vaca sobre o crescimento e produção de mudas de alface. O delineamento experimental utilizado foi em inteiramente casualizado, com quatro repetições. Foram analisados os efeitos de sete concentrações de urina de vaca $\left(1,0 ; 2,0 ; 3,0 ; 4,0 ; 5,0 ; 6,0\right.$ e 7,0\%) $\left(v^{-1}\right)$. Nas condições do sudoeste paranaense, 0 melhor desenvolvimento da alface foi obtido com a aplicação da concentração de 5,0\%. Os índices de clorofila (a e b), também foram superiores com a utilização da concentração de 5,0\%.

Palavras-chave: Lactuca sativa L. Agroecologia. Irrigação. Biofertilizante bovino. 


\section{INTRODUÇÃO}

Com o maior consumo e valor comercial no mundo, a alface (Lactuca saltiva L.), é utilizada em diversas formas na gastronomia, seu cultivo é de grande importância econômica e social, pois seu cultivo é realizado na sua maioria por pequenos produtores rurais (VILLAS BOAS et al., 2004).

Com grande destaque entre as olerícolas no estado do Paraná, a alface em 2018 obteve uma produção de 144.853,31 toneladas em uma área de 6.893,12 ha (SEAB, 2018). Apesar de figurar entre as olerícolas mais cultivadas no estado, sua produção ainda é muito concentrada na região metropolitana de Curitiba.

A região Sudoeste do estado do Paraná, se caracteriza por possuir pequenas propriedades de pequeno porte com mão-de-obra familiar, sendo adequada para o cultivo da alface, que apresenta grande retorno econômico por área cultivada (ZIECH et al., 2014).

Para uma expansão do cultivo da alface nas demais regiões do estado do Paraná, de forma rentável e livre de agroquímicos, o uso de biofertilizantes surge como uma alternativa. Chiconato et al. (2013) ao analisarem a resposta da alface com biofertilizantes, verificaram que esse insumo promoveu melhores resultados aos com adubação mineral.

Um dos insumos alternativos que vem ocupando espaço como proposta deste tipo de produção de hortaliças é o uso da urina bovina como fertilizante natural (FREIRE et al., 2019). A urina bovina é considerada um fertilizante agrícola que pode reduzir a dependência de produtos externos, já que esse recurso pode estar disponível em pequenas propriedades permitindo uma integração entre a pecuária e a horticultura (OLIVEIRA et al., 2009), reduzindo custos e servindo como fonte de nutrientes (ALENCAR et al., 2012), contudo, são escassos os estudos com este fertilizante (VERAS et al., 2020).

No entanto, as informações desse insumo para o crescimento de mudas de alface são insuficientes então objetivou-se com este trabalho avaliar o crescimento de mudas de alface crespas irrigadas com diferentes concentrações de urina de vaca no Sudoeste do Paraná. 


\section{MATERIAIS E MÉTODOS}

O experimento foi realizado no município de Sulina, localizado na região Sudoeste do Paraná, latitude $25^{\circ} 42^{\prime} 07^{\prime \prime}$ sul e longitude $52^{\circ} 43^{\prime} 20^{\prime \prime}$ oeste, com uma altitude de aproximadamente $470 \mathrm{~m}$. O Clima da região é classificado como Cfb (CAMARGO et al., 2016).

O experimento foi conduzido em uma estufa tipo arco com cobertura de filme plástico com 150 micras. Foram utilizadas bandejas de poliestireno expandido com 200 células para a produção das mudas, preenchidas com substrato comercial Plantmax ${ }^{\circledR}$ e semeadas com a cultivar de alface crespa Alcione, utilizando uma semente por célula.

A coleta da urina foi realizada em vacas em lactação, de rebanho leiteiro, realizandose a coleta de 15 vacas de plantel de sanidade comprovada em um único dia. Seu armazenamento foi realizado em recipiente plástico desinfectado, vedado e armazenado em abrigo. Sua utilização foi iniciada 48 horas após sua coleta (OLIVEIRA et al., 2010).

Os tratamentos foram constituídos de concentrações de 1, 2, 3, 4, 5, 6 e 7\% (v v-1) de urina de vaca em água deionizada. $O$ delineamento experimental utilizado foi realizado inteiramente casualizado (DIC), consistindo de sete tratamentos e quatro repetições. $A$ fertirrigação da urina foi realizada com um regador com um turno de rega de 1 dia. Em todas fertirrigações foram aplicados $250 \mathrm{~mL}$ do biofertilizante.

Aos 21 dias após a semeadura, foram avaliadas as seguintes características: altura da planta em milímetros: medição do coleto à projeção da folha central mais proeminente (FREIRE et al., 2019); número de folhas por planta e diâmetro do caule medido por paquímetro digital, a 2,0 cm do colo da planta (VERAS et al., 2020); comprimento da raiz através de uma régua mílimetrada (ARAGÃO et al., 2020); índices de clorofila (a e b): as leituras do clorofilômetro foram realizadas na terceira folha a partir do ápice. As leituras foram realizadas em triplicata, sendo tomadas entre 7 e 10 horas da manhã no dia da colheita. Todas as leituras foram realizadas no centro do limbo da folha. Utilizou-se um clorofilômetro da marca comercial Falker ${ }^{\circledR}$, modelo CFL 1030.

Os dados obtidos foram submetidos à análise de variância e quando significativos pelo Teste $F(p<0,05)$, as médias foram submetidas à análise de regressão, avaliando a significância dos coeficientes de determinação, utilizando o software MINITAB 18. 


\section{RESULTADOS E DISCUSSÃO}

A equação de regressão dos dados da altura da planta (Figura 1), demonstra que a medida em que se aumentou a concentração de urina de vaca houve um incremento na altura da planta, com a concentração máxima em $5 \%$, obtendo-se $43,8 \mathrm{~mm}$ de altura. Souza \& Resende (2006), apontam que o aumento na altura das plantas com uso da urina de vaca ocorre devido às propriedades químicas da urina de vaca, como potássio, nitrogênio, sódio, enxofre, cálcio, magnésio e fósforo. De maneira semelhante ocorreu com maior produção e desenvolvimento de abobrinhas (Cucurbita pepo L.) ao utilizar a concentração de $5 \%$ de urina de vaca (OLIVEIRA et al., 2003).

Figura 1 - Altura das mudas de alface crespa $(\mathrm{mm})$ em função de diferentes concentrações de urina de vaca.

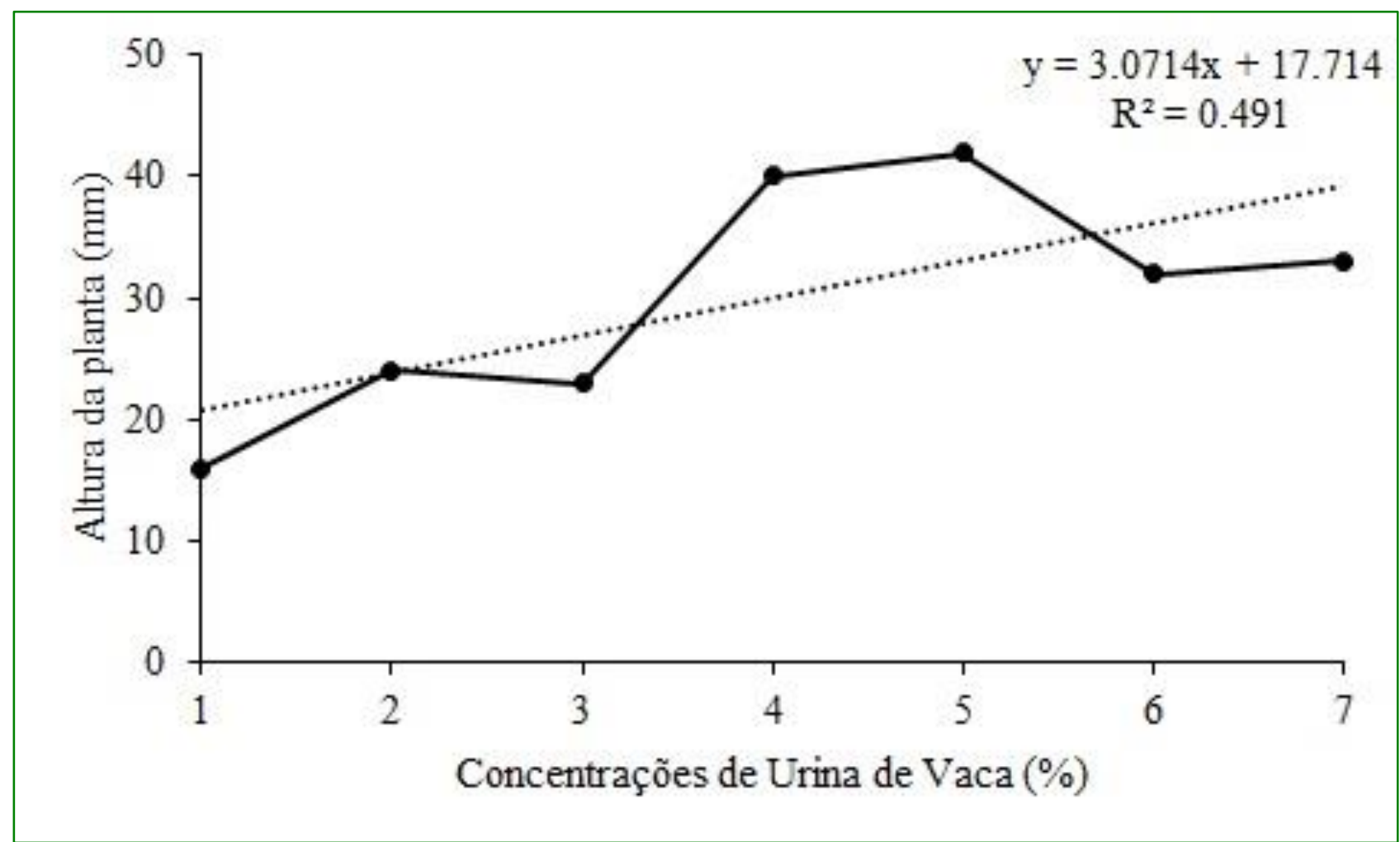

Fonte: Os autores.

Para o número de folhas por planta (Figura 2), manteve-se o padrão observado para a altura das plantas, com a concentração de $5 \%$, com o maior número de folhas $(4,27)$, tal aumento pode ser explicado pela promoção da urina de vaca no crescimento da parte aérea da planta, em termos de área foliar e de massa de folha (limbo e pecíolo) (OLIVEIRA et al., 2012). 
Figura 2 - Número de folhas das mudas de alface crespa em função de diferentes concentrações de urina de vaca.

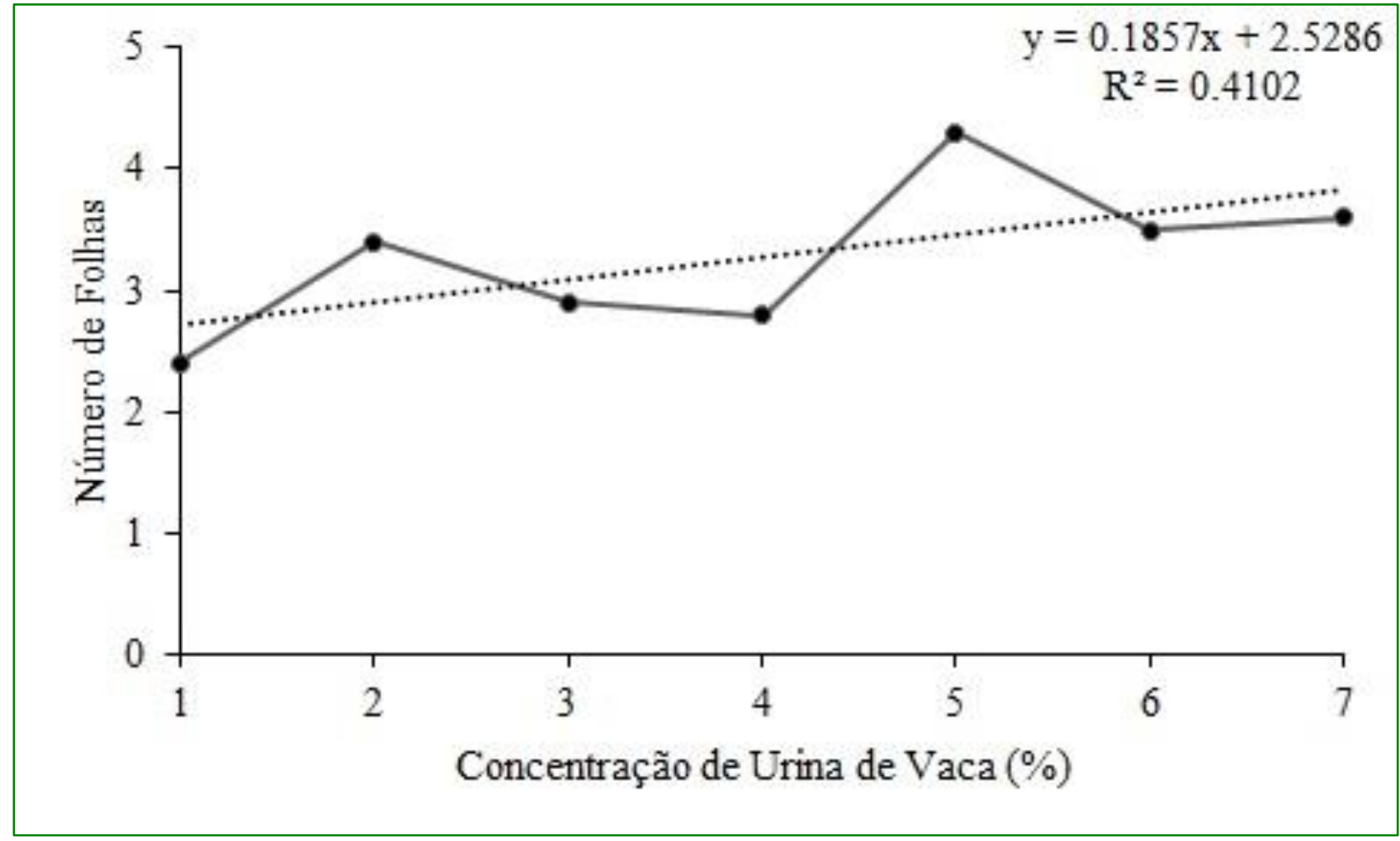

Fonte: Os autores.

O número de folhas obtido com todas concentrações foi superior ao costumeiramente recomendado, duas a três folhas, conforme observações de Trani et al. (2004). O aumento no número de folhas pode estar relacionado ao contato direto de gemas axilares com a urina de vaca, sendo que a citocinina presente na solução pode antagonizar o efeito inibitório promovido pela auxina, produzida pelo meristema apical da planta de alface, sobre o desenvolvimento das gemas (TAIZ \& ZEIGER, 2009).

Aplicando a análise de regressão pôde-se perceber que o aumento da dose aplicada proporcionou aumento no diâmetro do caule (Figura 3), sendo que o máximo diâmetro do caule $(7,03 \mathrm{~mm})$ foi obtido com a dose de $5 \%$ de urina de vaca. Estudos anteriores com outros compostos orgânicos como a torta de filtro (SANTANA et al., 2012) e biofertilizantes (DIAS et al., 2009) sugerem aumento no diâmetro caulinar da alface devido ao aumento de concentração do fertilizante. Para Oliveira et al. (2009), a promoção do crescimento do caule de alface com urina de vaca é explicada por outros fatores além da nutrição, como efeitos hormonais no alongamento celular, já que as quantidades de nutrientes nas 
aplicações com urina de vaca são inferiores a fertilização química/orgânica e muito pequenas para as necessidades nutricionais das plantas.

Figura 3 - Diâmetro de caule $(\mathrm{cm})$ das mudas de alface em função de diferentes concentrações de urina de vaca.

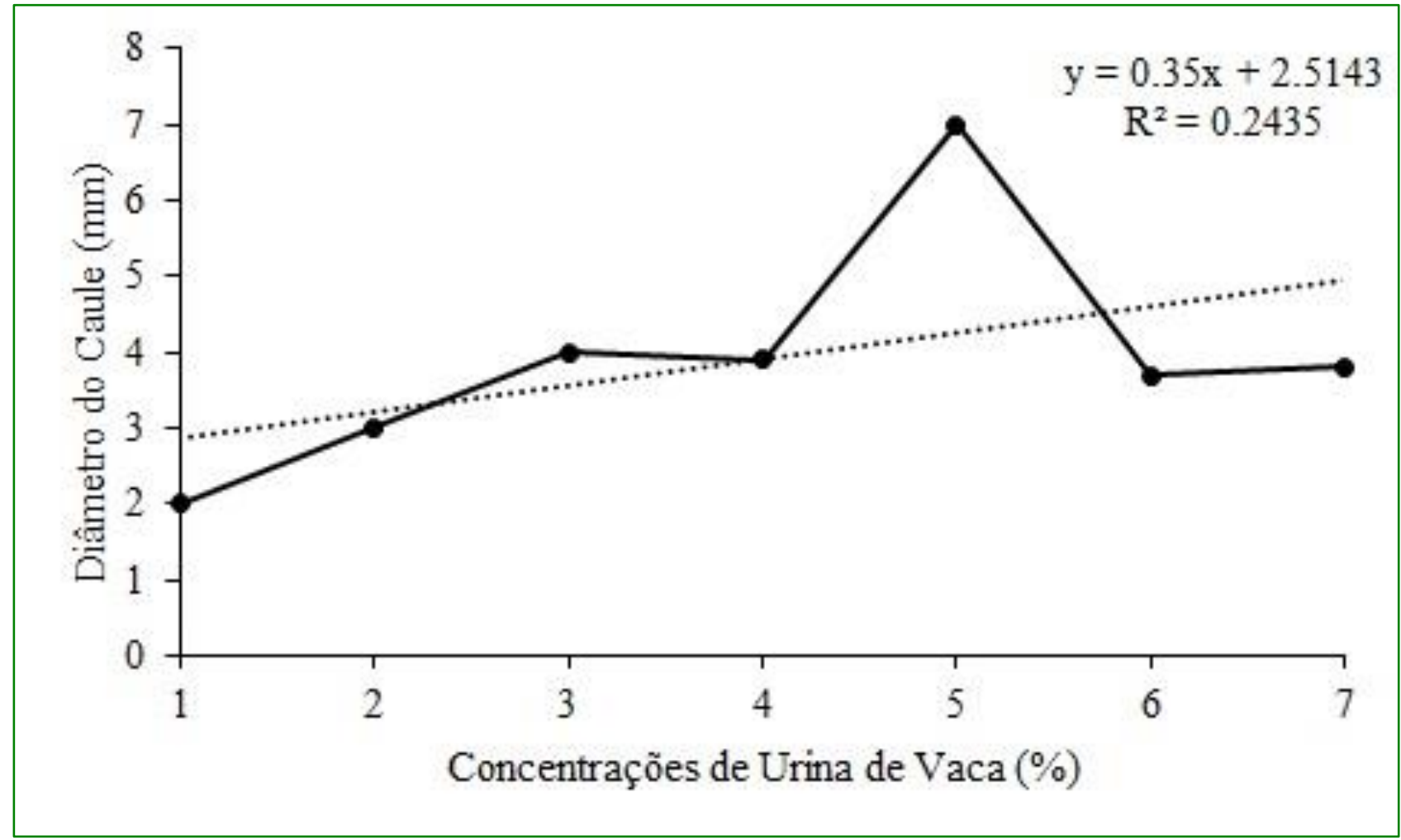

Fonte: Os autores.

As maiores raízes foram obtidas com a concentração de $5 \%$ de urina de vaca (Figura 4), com 83,2 mm. Esses resultados são de extrema importância, uma vez que podem ser correlacionados com a capacidade das raízes absorverem água e os principais nutrientes. Dessa forma, quanto maior o comprimento, maior será seu potencial de absorção de nutrientes (CECATO \& MOREIRA, 2013). Medeiros et al. (2007) ao estudarem a produção de mudas de alface com diferentes biofertilizantes e substratos concluíram que apenas o comprimento da raiz não obteve efeito positivo com compostos orgânicos.

A atividade fotossintética das plantas está diretamente relacionada com a clorofila, e a qualidade e a quantidade dessa clorofila com seu estado nutricional (VIEIRA et al., 2013). A Figura 5 revela os índices de clorofila 'a', com um crescimento linear, com o maior índice de clorofila sendo obtido com a dose de 5\% $(17,2)$. A cor verde intensa da alface, é um fator de atração para os consumidores, sendo considerada uma variável importante para a alface (SANTOS et al., 2001). 
Figura 4 - Comprimento da raiz de mudas de alface em função de diferentes concentrações de urina de vaca.

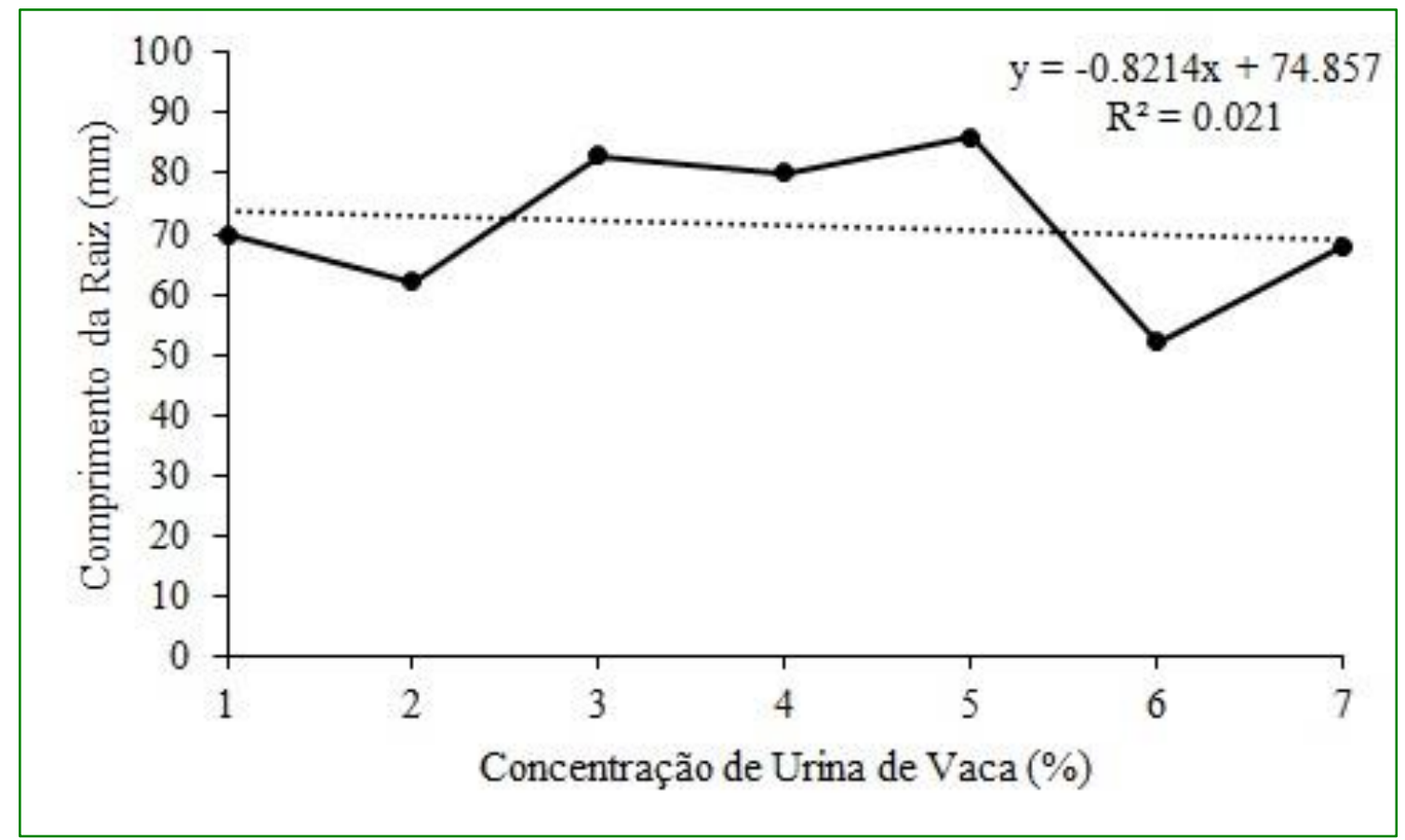

Fonte: Os autores.

Figura 5. Índices de clorofila (a) de mudas de alface em função de diferentes concentrações de urina de vaca.

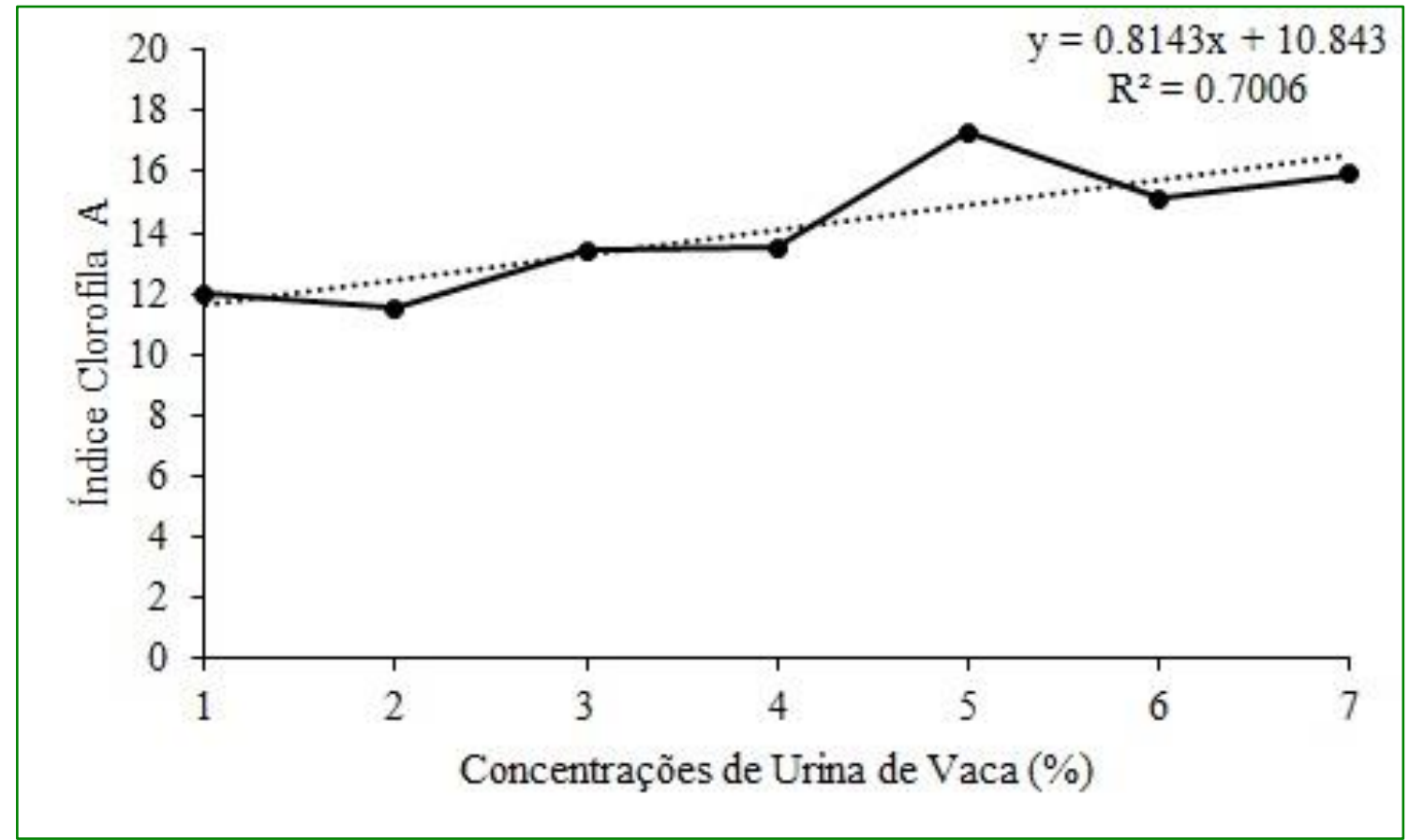

Fonte: Os autores. 
Ao analisar o índice de clorofila (b), observa-se um comportamento similar ao teor de clorofila 'a' com a concentração de $5 \%$ com o maior teor de clorofila 'b', com 3,38. Para Silva et al. (2015), urina de vaca proporciona melhoria de pigmentos clorofilianos em plantas de feijão-fava (Phaseolus lunatus L.).

Figura 6. Índice de clorofila (b) de mudas de alface em função de diferentes concentrações de urina de vaca.

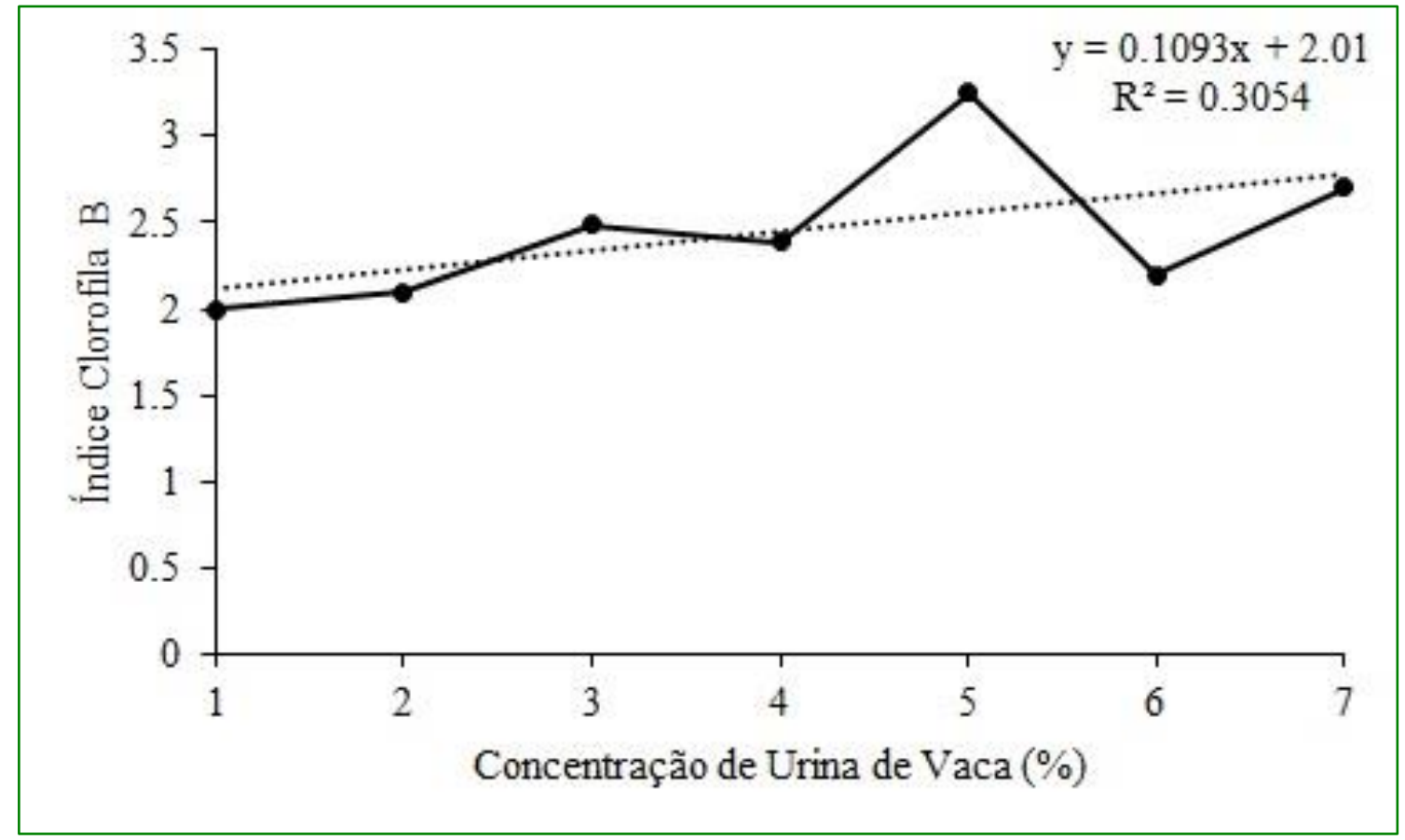

Fonte: Os autores.

\section{CONCLUSÕES}

Pode-se concluir que, de modo geral, concentrações de $5 \%$ de doses de urina de vaca proporcionaram maior crescimento e índices de clorofila.

Os resultados obtidos demonstram a potencialidade do uso da urina de vaca no Sudoeste do Paraná, para auxiliar no processo de produção de mudas de alface crespa conduzidas sob manejo orgânico. 


\section{REFERÊNCIAS}

ALENCAR, T. A. S.; TAVARES, A. T.; CHAVES, P. P.; FERREIRA, T. A.; NASCIMENTO, I. R. Efeito de intervalos de aplicação de urina bovina na produção de alface em cultivo protegido. Revista Verde de Agroecologia e Desenvolvimento Sustentável, v. 7, n. 3, p. 53-67, 2012.

ARAGÃO, M. M.; OLIVEIRA, G. R. C.; NEVES, J. L.; ANJOS, D. N. Resposta da cultura da alface em função de diferentes saturações por bases. Revista Pesquisagro, v. 3, n. 1, p. 94-101, 2020.

CAMARGO, L. E. O.; ROLIM, G. S.; RICHETTI, J.; SOUZA, P. S.; JOHANN, J. A. Köppen, Thornthwaite and Camargo climate classifications for climatic zoning in the state of Paraná. Ciência e Agrotecnologia, v. 40, n. 4, p. 405-417, 2016.

CECATO, A.; MOREIRA, G. C. Aplicação de extrato de algas em alface. Cultivando o Saber, v. 6, n. 2, p. 89-96, 2013.

CHICONATO, D. A.; DE SIMONI, F.; GALBIATTI, J. A.; FRANCO, C. F.; CARAMELO, A. $D$. Resposta da alface à aplicação de biofertilizante sob dois níveis de irrigação. Bioscience Journal, v. 29, n. 2, p. 392-399, 2013.

DIAS, N. S.; DE BRITO, A. A. F.; SOUSA NETO, O. N.; DE LIRA, R. B.; DE BRITO, R. F. Produção de alface hidropônica utilizando biofertilizante como solução nutritiva. Revista Caatinga, v. 22, n. 4, p. 158-162, 2009.

FREIRE, J. L. O.; SILVA, J. R.; NASCIMENTO, G. S.; SANTOS, F. F. S. Atributos de crescimento e produção de cultivares de alfaces irrigadas com águas salinas e uso de urina bovina. Agropecuária Científica no Semiárido, v. 15, n. 2, p. 124-131, 2019.

LOPES, J. C.; RIBEIRO, L. G.; ARAÚJO, M. G.; BERALDO, MRSBS. Produção de alface com doses de lodo de esgoto. Horticultura Brasileira, v. 23, n. 1, p. 143-147, 2005.

MEDEIROS, D. C.; LIMA, B. A. B.; BARBOSA, M. R.; ANJOS, R. S. B.; BORGES, R. D.; CAVALCANTE NETO, J. G.; MARQUES, L. F. Produção de mudas de alface com biofertilizantes e substratos. Horticultura Brasileira, v. 25, n. 3, p. 433-436, 2007.

OLIVEIRA, N. L. C.; PUIATTI, M.; SANTOS, R. H. S.; CECON, P. R.; RODRIGUES, P. H. R. Soil and leaf fertilization of lettuce crop with cow urine. Horticultura Brasileira, v. 27, n. 4, p. 431-437, 2009.

OLIVEIRA, N. L. C.; PUIATTI, M.; SANTOS, R. H. S.; CECON, P. R.; BHERING, A. S. Efeito da urina de vaca no estado nutricional da alface. Revista Ceres, v. 57, n. 4, p. 506-515, 2010.

OLIVEIRA, N. L. C.; PUIATTI, M.; BHERING, A. S.; CECON, P. R.; DA SILVA, G. C. C. Uso da urina de vaca no cultivo da beterraba de mesa. Revista Brasileira de Agropecuária Sustentável, v. 2, n. 2, p. 7-13, 2012. 
OLIVEIRA, N. L. C.; PUIATTI, M.; BHERING, A. S.; CECON, P. R.; SANTOS, R. H. S.; DA SILVA, G. C. C. Crescimento e produção da abobrinha em função de concentração e via de aplicação da urina de vaca. Revista Brasileira de Agropecuária Sustentável, v. 3, n. 2, p. 129-136, 2013.

SANTANA, C. T. C.; SANTI, A.; DALLACORT, R.; SANTOS, M. L.; MENEZES, C. B. Desempenho de cultivares de alface americana em resposta a diferentes doses de torta de filtro. Revista Ciência Agronômica, v. 43, n. 1, p. 22-29, 2012.

SANTOS, R. H. S.; SILVA, F.; CASALI, V. W. D.; CONDÉ, A. R. Conservação pós-colheita de alface cultivada com composto orgânico. Pesquisa Agropecuária Brasileira, v. 36, n. 2, p. 521-525, 2001.

SEAB (Secretaria de Estado da Agricultura e do Abastecimento). Olericultura - Análise da Conjuntura Agropecuária. 2018. Disponível em: http://www.agricultura.pr.gov.br/sites/default/arquivos_restritos/files/documento/201909/olericultura_2019_v1.pdf.

SILVA, L.; OLIVEIRA, D. L.; SANTOS, M. S.; BARROS, M. K. L. V.; BARROS, H. M. M. Desenvolvimento de espécies de pimentas sobre efeito de doses de urina de vaca. Revista Verde de Agroecologia e Desenvolvimento Sustentável, v. 10, n. 4, p. 26-31, 2015.

SOUZA, J. L.; RESENDE, P. Manual de horticultura orgânica. Viçosa: Editora Aprende Fácil. 2006. 843 p.

TAIZ, L.; ZEIGER, E. Fisiologia Vegetal. Porto Alegre: Artmed. 2009. 820 p.

TRANI, P. E.; NOVO, M. C. S. S.; CAVALLARO JÚNIOR, M. L.; TELLES, L. M. G. Produção de mudas de alface em bandejas e substratos comerciais. Horticultura Brasileira, v. 22, n. 2, p. 290-294, 2004.

VERAS, M. L. M.; ALVES, L. S.; IRINEU, T. H. S.; LIMA, V. L. A.; DO Ó, K. D. S.; ANDRADE, R. Resposta do girassol à irrigação e aplicação de fertilizantes orgânicos. Irriga, v. 25, n. 1, p. $46-57,2020$.

VIEIRA, J. H.; DIVINCULA, J. S.; SANTOS, L. A.; SANTOS, R. S. S.; DE SÁ, M. B.; DOS SANTOS, M. A. L. Resposta dos teores de clorofila da alface a doses de fertirrigação de NPK e lâminas de irrigação. In: INOVAGRI INTERNATIONAL MEETING, 2001, Fortaleza. Resumos.. Fortaleza: ABID, 2001.

VILLAS BOAS, R. L.; PASSOS, J. C.; FERNANDES, D. M.; BÜLL, L. T.; CEZAR, V. R. S.; GOTO, R. Efeitos de doses de compostos orgânicos na produção de alface em dois solos sob ambiente protegido. Horticultura Brasileira, v. 22, n. 1, p. 28-34, 2004.

ZIECH, A. R. D.; CONCEIÇÃO, P. C.; LUCHESE, A. V.; PAULUS, D.; ZIECH, M. F. Cultivo de alface em diferentes manejos de cobertura de solo e fontes de adubação. Revista Brasileira de Engenharia Agrícola e Ambiental, v. 18, n. 9, p. 948-954, 2014. 


\begin{abstract}
The use of cow urine can be considered an agricultural practice of low cost for farmers in Southwest Paraná. This work aimed to evaluate the effect of cow urine on growth and production of lettuce seedlings. The experimental design was completely randomized with four replications. We analyzed the effects of seven cow urine concentrations $(1,0,2,0,3,0$, $4,0,5,0,6,0$ and $7,0 \%)\left(v^{-1}\right)$. In the conditions of Southwest Paraná, the best lettuce development was obtained with the application of 5,0\% concentration. Chlorophyll indices ( $a$ and $b$ ), were also higher with the use of concentration $5,0 \%$ concentration.
\end{abstract}

Keywords: Lactuca sativa L. Agroecology. Irrigation. Bovine biofertilizer.

\title{
RESUMEN
}

La utilización de la orina de vaca puede ser considerada una practica de bajo costo para los productores rurales del Suroeste de Paraná. Así, con este trabajo se objetiva evaluar el efecto de la orina de vaca sobre el crecimiento y producción de plántulas de lechuga. El delineamento experimental utilizado fue enteramente casualizado, con cuatro repeticiones. Fueron analizados los efectos de siete concentraciones de orina de vaca $(1,0 ; 2,0 ; 3,0 ; 4,0$; $5,0 ; 6,0$ y $7,0 \%)\left(v^{-1}\right)$. En las condiciones del suroeste paranaense, el mejor desarrollo de la lechuga se demostró con la aplicación de la concentración de 5,0\%. Los índices de clorofila (a y b), también fueron superiores con la utilización de la concentración de 5,0\%.

Palabras clave: Lactuca sativa L. Agroecologia. Irrigación. Biofertilizante bovino. 


\section{LICENÇA DE USO}

Este é um artigo publicado em acesso aberto (Open Access) sob a licença Creative Commons Atribuição 4.0 Internacional (CC BY 4.0), que permite uso, distribuição e reprodução em qualquer meio, desde que o trabalho original seja corretamente citado. Mais informações em: http://creativecommons.org/licenses/by/4.0

\section{CONFLITO DE INTERESSES}

Os autores declaram que não há conflito de interesses neste trabalho.

\section{CONTRIBUIÇÕES AUTORAIS}

Ricardo Júnior Marangon: Responsável pelo levantamento de dados, geração de gráficos e análise estatística.

Marcelo Dotto: Responsável pela coordenação e orientação do experimento.

Allan Remor Lopes: Responsável pela revisão e redação do trabalho.

Camila Moreno Giarola: Responsável pela revisão e redação do trabalho.

Kelli Pirola: Responsável pela revisão e redação do trabalho.

\section{COMO REFERENCIAR}

MARANGON, Ricardo Júnior; DOTTO, Marcelo; LOPES, Allan Remor; GIAROLA, Camila Moreno; PIROLA, Kelli. Urina de vaca influencia o crescimento de mudas de alface crespa no Sudoeste do Paraná? Revista Brasileira de Engenharia de Biossistemas (Tupã), v. 15, n. 1, p. 142-153, 2021. DOI: http://dx.doi.org/10.18011/bioeng2021v15n1p142-153.

\section{RESPONSABILIBADE EDITORIAL}

Prof. Dr. Fernando Ferrari Putti ${ }^{1}$, Prof. Dr. Paulo Sérgio Barbosa dos Santos ${ }^{1}$, Prof. Dr. Eduardo Festozo Vicente ${ }^{1}$ e Prof. Dr. Diogo de Lucca Sartori ${ }^{1}$

${ }^{1}$ Universidade Estadual Paulista "Júlio de Mesquita Filho", FCE - Faculdade de Ciências e Engenharia, Tupã, SP, Brasil. 